\title{
Apoptosis in amphibian development
}

\author{
Jean-Marie Exbrayat, Elara N. Moudilou, Lucie Abrouk, Claire Brun
}

Université de Lyon, UMRS 449, Biologie Générale, Université Catholique de Lyon, Reproduction et Développement Comparé, Ecole Pratique des Hautes Etudes, Lyon, France

Email: jmexbrayat@univ-catholyon.fr

Received 13 August 2012; revised 20 September 2012; accepted 28 September 2012

\begin{abstract}
Amphibians and more particularly $X$. laevis are models often used for studying apoptosis during embryonic development. Using several methods, searchers determined the localization of programmed cell deaths (PCD). Several experimental methods also have been used to understand the regulatory mechanisms of apoptosis, throughout development, contributing to elucidate the general action of several genes and proteins. Apoptosis occurs very early, with a first program under control of maternal genes expressed before MBT, in order to eliminate damaged cells before gastrulation, and a second program at the onset of gastrulation. PCD is also observed during neurulation. Then, apoptotic cells are observed in amphibian organogenesis and metamorphosis. Results of these researches showed both importance of PCD for embryonic development, and the complexity of its regulation. Results obtained can be useful to understand others aspects of the importance of apoptosis, particularly pathological aspects.
\end{abstract}

Keywords: PCD; Apoptosis; Development; Metamorphosis; Amphibian; Xenopus

\section{INTRODUCTION}

Amphibians reproduce in water with an external or internal development at the end of which the tadpole or larva brings on metamorphosis, turning in a terrestrial adult. Apoptosis being a major event on metamorphosis, amphibians, and more especially Xenopus laevis are useful models to study programmed cell death [1-4]. A synthesis of works about apoptosis, obtained from amphibians is given here.

\section{GENERAL ASPECTS OF EMBRYONIC DEVELOPMENT IN AMPHIBIANS}

Eggs and early embryos of amphibians are characterized with the presence of a pigmentation which clearly indicates a bilateral symmetry. Fertilized eggs immediately divide to give the first two blastomeres which continue to divide becoming a morula. An inner cavity, the blastocoel, appears in the mass cell of the embryo, becoming a blastula. During this period of cleavage, the size and shape of embryos do not vary. Before mid blastula transition (MBT), zygotic genes do not express excepted those encoding for proteins implicated in membrane building. Maternal mRNAs previously accumulated in the oocytes remain present in the cytoplasm of zygote and they are distributed into the cytoplasm of blastomeres during cleavage. These maternal mRNAs encode for proteins which will be implicated in expression of zygotic genes. In post-MBT, zygotic genes express according to maternal signals. After cleavage, cells displace during gastrulation, at the end of which ectoderm, mesoderm and endoderm are installed. The archenteron or primitive intestine is observed. After gastrulation, on the dorsal part of the embryo, the neurectoderm originnates successively the neural plate, then neural folds which fuse to form the neural tube. The dorsal part of mesoderm differentiates onto notochord and somites. After neurulation, the end of which being characterized by "tail-bud" stage, organogenesis occurs. After a growth period, metamorphosis occurs. This phase corresponds to the transfer from an aquatic to a terrestrial life and it is characterized by the modification, development, or regression of several organs.

\section{APOPTOSIS AT EARLY STAGES: SEGMENTATION AND GASTRULATION}

\subsection{Repartition of Apoptotic Cells during Normal Development}

Repartition of apoptotic cells in early stages of development has been little described [5-7] but consistent data have been published in developing $X$. laevis [8]. At the beginning of development, first TUNEL positive cells appear in embryos at the onset of gastrulation. Staining was first observed such as spots or symmetric masses in the region surrounding the blastopore. Apoptotic cells were also found in the remaining blastocoel. Histological 
investigations showed the presence of apoptotic cells on ectoderm and internal mesoderm. At the end of gastrulation, apoptotic cells described a dorsal median strip or two parallel strips on the dorsal part of embryo, showing the place of future neural plate. TUNEL positive cells were found in both neuroectoderm and underlining mesoderm. Degenerative cells were also observed in the Japanese newt Cynops pyrrhogaster [7]. At the onset of gastrulation, strongly pigmented cells were observed in ectoderm and in the blastocoel. In old gastrulae, cells showing a similar aspect were found in ectoderm, on contact with archenteron. At the end of gastrulation, two groups of pigmented cells were localized into the residual blastocoel and in the anterior part of archenteron. Dead cells in Cynops pyrrhogaster and X. laevis showed a similar repartition. In developing zebrafish Danio rerio dead cells also presented a corresponding repartition [9, 10], showing this phenomenon of cell death at gastrulation is general in lower vertebrates.

\subsection{Regulation of Apoptosis during Segmentation and Gastrulation}

To understand the regulation of apoptosis, experimentations have been performed on early development stages in $X$. laevis [11-13]. After irradiation with $\gamma$ rays damaging DNA before the first cleavage, embryo continued to cleave. The 12 first cycles of divisions were perfectly comparable to that of control animals with additional divisions. Irradiated DNA being shorter than normal one, its replication was faster, explaining the presence of additional divisions. So, the time of segmentation used to attempt gastrulation was genetically regulated by a timer. In embryos DNA of which being broken with restriction endonucleases before the first division, synchronization of cleavages was not perturbed and time to attempt gastrulation was not modified. So, embryonic DNA was not implicated in control of these cell cycles.

In two cells-embryos treated with $\alpha$ anamitine in order to inhibit transcription, segmentation was no effected. In embryos treated with cycloheximide, an inhibitor of protein synthesis, cell division was stopped one hour after the treatment. In embryos treated with a mixture of aphidilcoline and hydroxyurea used to block replication of DNA, the segmentation was also stopped. All these treatments consequently provoked a rapid and synchronous death of embryos at the onset of gastrulation with cells showing apoptotic characteristics. In addition, a caspase activity was shown in extracts of irradiated embryos at stage 10.5, contrarily in non-irradiated cleaving embryos or gastrulae.

Two programs of cell death from segmentation to tadpole stage have been observed [12]. One of these programs was activated at the onset of gastrulation, conse- quent to the degradation of cells occurring before MBT. It was supposed that the degradation of these non stable cells was programmed by maternal genes, according to a biological timer independent on the type of stress, cell progression, or protein synthesis. A second program of cell death started at gastrulation in normal embryos. In embryos of $X$. laevis treated with hydroxyurea, an instability of cyclins A1 and A2 was observed at the onset of gastrulation [14]. At this period, zygotic transcription was necessary to suppress apoptosis in normal embryos. In treated animals, it was not possible to maintain such an inhibition and consequently a lot of apoptotic cells were observed. So, the apoptotic program was suppressed in early blastulae by maternal inhibitor, and the degradation of mRNAs encoding for apoptosis inhibitors before MBT, was then compensated with a new zygotic transcription between MBT and gastrulation. In other experiments, apoptosis was blocked with injection of mRNAs encoding for BCl-2. Results confirmed that maternal program was blocked with inhibitor of apoptosis. In animal submitted to low doses of cycloheximide, development was delayed before MBT but DNA synthesis, and transcription started normally at the onset of gastrulation. All these results suggested the existence of a checkpoint at MBT, regulated by maternal genes in order to start apoptosis and also showed that zygotic transcripttion could block maternal program of apoptosis [15].

The lengthening of cell cycle from MBT was due to an increase of phosphorylation of Tyr16 belonging to cdc2. Resistance to apoptosis was associated to an increase of p27 Xie1, a part of $B C l-2$ or Bax-2 implicated in pro- or anti-apoptotic complexes, and an increase of protein kinase Akt. At MBT, the degradation of cyclin E was also regulated by an internal timer insensible to the inhibition of DNA, mRNAs and proteins [16], provoking apoptosis at gastrulation [6]. An injection of cyclin A2 suspension did not affected early development and the embryos were able to attempt tail-bud stage if cdk2 was added. After MBT, an injection of cyclin A2/cdk2 characteristic of G1/S phases provoked a cell proliferation, more especially in the future epidermis disturbing the equilibrium between division and differentiation.

In $X$. laevis, the maternal program of apoptosis was activated just after MBT with an over-expression of $S$ adenosyl mathionine carboxylase [17], provoking a lack of S-adenosyl methionine. Embryos developed in blastula, but stopped at the onset of gastrulation at which cells became apoptotic. This destruction was stopped with an injection of $B C l-2$ mRNA. In embryos receiving micro injection of 5-aza-CdR inducting hypomethylation of DNA, or 5-methyl dCTA, inducting contrarily a hypermethylation, cleavage was normal but embryos became apoptotic at gastrulation [18]. Apoptosis was suppressed in embryos injected with an inhibitor of caspases 
and the activation of caspase-9 was a stage-key for the activation of maternal program [19]. XChk1 provoked an elongation of cell cycle [20]. If Chk1 was inhibited, the development was normal until the onset of gastrulation at which the embryo died, with cells entering in apoptosis. In zygotes with two blastomeres injected with $S A M D L$ mRNAs, apoptosis was also observed at gastrulation [21, 22]. If these mRNAs were injected on a side only in embryos with 4 to 8 cells, a large number of animals became tadpoles; if embryos were 16 to 32 cells, all individuals became tadpoles with sometimes abnormalities. Apoptotic cells originating from injected blastomeres were found in blastocoel, even in developing embryos. Other molecules have been signaled in order to participate to the check- point of apoptosis [23]. High levels of p27BBP/eIF6 have been observed during development when PCD increased. This anti-apoptotic factor was related to an increase of apoptosis in the parts of embryos needing cell death for harmonious development [24]. Several experiments based upon the over-expression of FoxO genes in $\mathrm{X}$. laevis showed these genes were indispensable for tissue differentiation but not for gastrulation, even overexpression of several of them induced severe damages in gastrulae [25]. Bix expressed in early Xenopus gastrula, and an over-expression as well as a depletion of Bix3 causes apoptosis [26].

In other vertebrates, embryos also exhibit the activetion of surveillance mechanisms, early in development, to produce the selective apoptosis of damaged cells like in amphibians. [27].

The interactions between embryonic layers were studied in order to understand regulation of balance between cell survival and apoptosis [28]. Glucocorticoid-inducible kinase 1 (SGK1) promoted ectodermal cell survival during early Xenopus embryogenesis. A dorsal depletion of SGK1 resulted in modified morphology. In transgenic embryos, a knockdown of SGK1 caused apoptosis in the ectoderm. SGK1 also stimulated production of BMP7. Finally the existence of chain of reactions with an endodermal and mesodermal pathway from PI3K to SGK1 to the transcription nuclear factor producing BMP7 was demonstrated, promoting ectodermal survival by decreasing Death Inducing Signaling Complex function. In Xenopus, maternal p53 mRNAs and proteins seem to be essential for development [29].

\section{APOPTOSIS AT EARLY STAGES: NEURULATION}

\subsection{Description of Apoptosis in Normal Development}

The presence of apoptotic cells was detected during neurulation of $X$. laevis [8]. At stage 13, apoptotic cells visualized were localized on the dorsal part of embryo, generally distributed on two strips or a single median strip, delimitating the neural plate from blastopore to the dorsal part of body. Apoptotic cells were localized in the neuroectoderme and the underlining mesoderm. At stages 14 and 15, TUNEL labeled cells were grouped on the anterior part of neural plate. At stages 16 and 17, apoptotic cells were particularly numerous on both the anterior and dorsal parts of embryos, corresponding to nervous system. The most intense TUNEL staining corresponded to the presence of primary sensorial neurons. Staining was particularly intense in the region of future brain, at the place of olfactive and otic placodes. Comparable data have been obtained in the zebrafish Danio rerio [9]. At the end of the stage of neural plate, the number of apoptosis decreased comparatively to previous stages. In some embryos, apoptosis were also visualized in the notochord [30], and they became more and more numerous till the end of neurulation, with an anterio-posterior pattern of distribution. If apoptosis was inhibited in mesodermal explants of notochord, this one became twice longer than in control, but in some embryos, notochord lacked a recognizable structure, apoptotic cells were observed in the tail but somites were not affected. Apoptotic cells appeared in neural crests. From stage 26 to 28, apoptotic cells were distributed in two symmetric areas in brain, and also observed in eyes, spinal cord and tail. Cell deaths were also observed on neural tube in two neurulae of Cynops pyrrhogaster, with a distribution like in $X$. laevis [6].

\subsection{Regulation of Apoptosis at Neurulation}

During neurulation, several primary neurons visualized with $\mathrm{N}$ tubulin became apoptotic, like in sensorial placodes in which apoptosis were observed prior the formation of synapse. In $X$. laevis, this part of embryo was under the expression of the homeobox gene $X o t x 2$ but, at the beginning of neurulation, the expression of $X r x 1$ occurred and expression of Xotx 2 stopped. The first definition of the territories of retina on diencephalon in early neurulae resulted from the repression of Xotx2 by Xrx1. So, $X r x 1$ could be implicated on properties of the anterior part of neural plate in order to develop the anterior brain and eyes [31]. In X. laevis embryos in which cell proliferation was blocked, the spatio-temporal pattern of apoptosis remained unaffected in neuroectoderm if they contained half the normal number of cells. An over-expression of $\mathrm{Bcl}$-2 during primary neurogenesis of Xenopus embryos stopped PCD. After inhibition, the normal neurogenesis was disrupted with perturbation of expression domains of several genes. Yet, inhibition of PCD did not affect the outcome of lateral inhibition. These experimentations demonstrated that PCD regulated primary neurogenesis at the level of neuronal determination [32]. 
In Xenopus POSH (Plenty of SH3s) was implicated in the development of anterior brain, and essential for apoptosis when it was mediated by c-Jun N-terminal kinase (JNK) [33]. The importance of expression of gene XBtg2 was demonstrated in Xenopus neural development [34]. The expression of this gene was found on the anterior part of neural plate and the neural crests at midneurula stage. If XBtg was inhibited on only one side of embryo, formation of eyes became impaired, and the anterior neural development disrupted. In embryos in which XBtg2 was depleted, a decrease in the expression of neural genes was observed in anterior brain, but neither in neural crests nor in epidermis, suggesting XBtg2 implicated for the differentiation of the anterior neural plate in which its depletion provoked an increase of both cell apoptosis and proliferation.

In $X$. laevis, $m s x 1$ gene acted as a factor promoting apoptosis, and Slug gene acted as an anti apoptotic factor [35-39]. Both the anti-apoptotic gene $B c l-2$ and the apoptosis-promoting gene Bax disturbed the expression of these genes. A Slug over-expression provoked an enlargement of the neural crests and derivatives. Region of neural crests in which Slug was expressed, did not undergo apoptosis, and region in which $m s x 1$ was expressed became apoptotic in the part of neural folds adjacent to the neural crest. The balance between these two antagonist genes controls the formation of neural crest cells and derivatives. Prohibitin 1, an inhibitor of cell proliferation, presented a function in development of neural crests. Its gene $X p h b 1$ was maternally and zygotically expressed. In neurula transcripts, it accumulated in the neural tube and the neural crests [40]. Inhibition of Prohibitin 1 resulted in the loss of expressions for several genes whereas other genes were not affected. E2F1binding domain was necessary for the action of $X p h b 1$ in development of neural crests [40].

The repartition of p27BBP/eIF6, a protein the decrease of which was accompanied by a reduction in proliferation of several cells in eIF6 mice, was studied throughout the development of Xenopus [41]. At the beginning of embryogenesis, a correspondence between highest levels of p27BBP/eIF6, cell proliferation and apoptosis was observed. In later development stages high proliferation levels were present in the same regions where higher $p 27 B B P / e I F 6$ expression was observed, while apoptosis were not concentrated in the same sites. So, a high presence of p27BBP/eIF6 would appear in the regions where cell death is essential for normal development [41].

\section{APOPTOSIS DURING ORGANOGENESIS AND GROWTH PERIOD}

Between stages 35 and 39, a high number of apoptotic cells were observed in the whole organism, but the organs essential for a free life did not present any dead cells. Dead cells were observed especially in ventral part of the prosencephalon and in spinal cord. The retina presented two phases of cell death [42], one at stages 37 - 38 in the ventronasal part of retina, and the other at stage 47 in retinal ganglion cell layer [43]. At stage 46, when the hind limbs appeared [2], TUNEL positive cells were mainly observed in the epidermis and the first generation of gills. Few apoptosis were then observed in the second generation of gills. During the period at which the cement gland, a transitory organ, began to degenerate, nervous system and several organs presented numerous dead cells [44]. At these stages, tadpoles were very sensitive to environmental changes and became fragile [1, 43]. During the end of the growth period up to stage 52, no massive cell death occurred.

\section{APOPTOSIS AT METAMORPHOSIS}

\subsection{Several Aspects of Apoptosis at Metamorphosis}

Amphibian metamorphosis involves dramatic remodeling of organs, so a large quantity of apoptosis occurs permitting the replacement of larval organs and tissues with the adult ones. In $X$. laevis, metamorphosis is three days long, and the end is characterized by the entire regression of the tail [45-51]. Amphibian metamorphosis is a good model to understand the mechanisms regulating PCD [52-54]. The tail regression implicates an apoptotic pathway inducible by T3 hormone and involving some cell death executioners [55].

At the onset of metamorphosis, numerous apoptotic cells were observed in the spinal cord and caudal spinal ganglia $[43,47,56]$, and a caspase-3 activity increased during climax in the spinal cord [48]. At stage 58, a peak of apoptosis was observed in spinal cord $[43,56]$. The number of limb motoneurons decreased strongly after limb innervations [57-59]. From stage 61, cell death in the spinal cord was increasingly observed affecting motoneurones and ependymal cells. PCD in the motoneurons started behind the onset of PCD involving sensory neurons $[43,56])$. At stage 64 , some nervous cells were still observed in the residue of the tail [60]. The elimination of several retinal ganglia cells occurred during climax [61,62]. It was supposed that the process of optic nerve remodeling accompanied the displacement of eyes from lateral to more dorsal and rostral position as the frog acquired binocular vision studied [62,63]. The competition for target sites might also modulate retinal PCD [64]. Cell deaths were also observed in some brain regions such as mesencephalon and diencephalon. The number of apoptotic cells in the brain increased at the onset of metamorphosis. At stage 61 numerous apoptotic 
cells were observed in the thalamus and mesencephalon. The primary sensory Rohon-Beard neurons [65] and the giant Mauthner's neurons in the hindbrain regressed during metamorphosis, between stages 50 to 55 [66,67]. The expression of the $x R 11$ gene prolonged the survival of the Rohon-Beard cells and limited the morphological changes of Mauthner's cells $[67,68]$ but did not affect the disappearance of motoneurons of spinal cord.

At climax, the muscles of the tail totally regressed [10, 45]. At stage 57, muscle cells began to be altered [40,51] and fast muscular fibres were deleted first [59]. At stage 62, TUNEL positive cells of muscle were detached from the extracellular matrix and died [60] and finally caudal muscles were removed [53,69]. Cell death occurred also in the dorsal muscles which do not express the adult contractile proteins, in order to be progressively replaced with adult muscle [70]. Caspase-3 activity and Bax mRNA [71] increased in muscle cells during the climax, suggesting that death of tail muscle cells implicates a caspase-dependent pathway. Bax gene is regulated during metamorphosis [72]. The regression of tail implicates an apoptotic pathway inducible by T3 hormone [58]. Caspase 9 mRNA was expressed in the tail before metamorphosis and increased before and during climax, the production of active forms of caspase 9 increased in muscle tissue as metamorphosis progressed [73].

At metamorphosis, the cells of larval intestine became apoptotic, and they were replaced with non-differentiated cells in order to form adult intestine [74-76]. TR $\beta$ participated to apoptosis of larval intestine; close relationship between the epithelium and the connective tissue was evident during the intestinal remodeling [77-79]. The occurrence of apoptosis was also demonstrated in the different parts of digestive tract during metamorphic remodeling in Rana pipiens and Ceratophrys ornata larvae [80]. Matrix metalloproteinase MMP-9TH was responsible of apoptosis in the larval epithelial through degrading ECM components in the basal lamina, whereas MMP-9 was involved in the removal of dying epithelial cells during intestinal remodeling [81]. Digestive tract was remodeled under the control of epithelial-connective tissue interactions. In larval epithelial, cells underwent apoptosis, while a small number of stem cells proliferated and differentiated to form adult epithelium [82]. In liver, gene expression changed drastically but no major morphological changes were observed [76].

In the skin, the outer two-cell layers of the epidermis died by apoptosis during the climax [59], showing the presence of caspase-3 [83]. At metamorphosis, number of larval red blood cells decreased whereas adult ones increased. During metamorphosis, many larval red blood cells expressed TUNEL-positive reactions in the spleen [84].

\subsection{Regulation of Metamorphosis and Apoptosis}

Thyroid hormones, T3 and T4 start amphibian metamorphosis [51]. T3 and T4 concentrations present a peak at stages 58 to 66. Thyroid hormones regulated genes expression through its nuclear receptors (TRs). In Xenopus, TR $\beta$ genes were highly expressed only during metamorphosis [85]. Xenopus TR $\beta$ genes were regulated in a cell-type specific manner [86], and implicated in both inducing apoptosis and stimulating cell proliferation. TRs could form heterodimers with retinoic receptor binding with the thyroid hormone response element situated in the target gene promoter which they active in presence of thyroid hormone during metamorphosis, so thyroid hormone receptors and 9-cis retinoic acid receptors were required for mediating the regulation of the genes $[49,87,88]$. Many genes were up-and down-regulated by thyroid hormone in the regressing tail [89]. TH also played a direct role in neurogenesis during development of connections between the spinal cord and limbs.

The developmental expression of thyroid hormone response genes, encoding extracellular matrix-degrading metalloproteinases, suggested that extra cellular remodeling plays an important role, including cell death, cell proliferation and differentiation. Since some years, studies concerning the role of extra-cellular matrix have been published, showing its importance on metamorphosis [87, 90-93]. The expressions of MT1-MMP and GelA genes were studied in intestine and tail of $X$. laevis during metamorphosis [92]. Both genes were up-regulated when both organs underwent metamorphosis. MT1-MMP only was also expressed in the longitudinal muscle cells of the metamorphosing intestine. MT1-MMP and GelA function together in the extracellular matrix degradation or remodeling with independent roles in muscle development in the intestine. At the onset of metamorphosis, the expression of lamin LA was down-regulated, but that of lamin LIII was up-regulated only in the islets of progenitor cells [94]. Then, the expression of LA became up-regulated, whereas that of LIII became down-regulated in the adult cells. Results suggested the involvement of the lamins in the process of dedifferentiation during amphibian metamorphosis.

Concentration of intracellular calcium is one of the factors that can modulate apoptosis. So, an excessive influx of extracellular calcium can activate enzymes which participate to cell death. Consequently, an activation of ionotropic receptors like AMPA/kainate receptors permeable to calcium may participate to the elevation of intracellular calcium. In $X$. laevis, calpains, auxiliaries of signal transduction for apoptosis [95], could be implicated during events of metamorphosis when activated by calcium [43]. In order to understand these complex 
mechanisms, in a first time, units GluR2/3 of AMPA/ Kainate receptors were in several organs of $X$. laevis tadpoles in stages 50 and 54 [96], other organs remaining negative. In central nervous system, periventricular radial cells, motoneurons and ganglia cells were also visualized. Then, apoptotic cells were visualized in $X$. laevis embryos from hatching to climax [56]. Several organs always contained apoptotic cells. Transitory organs were affected by apoptosis only at regression period. Nervous cells degenerate, with a peak of apoptosis at stage 58, just before tail regression. The effect of NBQX, an antagonist of AMPA/kainate receptors of glutamate on PCD was researched in tadpole of $X$. laevis at stage $46[97,98]$. The ubiquity of calpains $1,2,3$, was observed in all the organs, with a weak expression at early stages, increaseing in tadpoles and decreasing at metamorphosis [99]. In NBQX treated animals, the number of apoptotic cells increased variably in the organs, with a stronger label in those particularly affected by metamorphosis $[97,98]$.

\section{CONCLUSION}

Amphibians, with more particularly $X$. laevis and $X$. tropicalis [100], but also other species [6,80,101] are useful models for studying apoptosis during embryonic development. For that, it was first necessary to give a table of development. So, the normal table of $X$. laevis [2] is a useful tool. In order to understand apoptosis during normal development, searchers determined first the localization of cell deaths. Then, several experiments permitted to understand the mechanisms of apoptosis throughout development, contributing to elucidate the general action of several genes and proteins in its regulation. Apoptosis occurs very early, with a first program under control of maternal genes used to eliminate damaged cells before gastrulation, and a second program at the onset of gastrulation. PCD was also observed during neurulation. In mice, the role of apoptosis was studied in the regulation of forebrain development [102]. In mice in which genes $J n k 1$ and $J n k 2$ have been deleted, no apoptotic cells were observed at stage of neural fold, and the posterior part of hindbrain remained open in advanced embryos; in mice for which caspase-3 was deficient, the cerebral wall thickened with a convoluted area of cortex in surviving embryos. Then, PCDs were observed in amphibian organogenesis and metamorphosis. Results of these researches showed both the complexity of PCD and its importance for embryonic development. They can also be useful to understand others aspects of the importance of apoptosis, particularly in pathologies.

\section{REFERENCES}

[1] Estabel, J. König, N., Shiokawa, K. and Exbrayat, J.M.
(2005) Apoptosis in Xenopus genus. In: Scovassi, I., Ed., Apoptosis, Research Signpost, Trivandrum, 147-156.

[2] Nieuwkoop and Faber (1967) Normal table of Xenopus laevis (Daudin). North Holland, Amsterdam.

[3] Schreiber, A.M., Cai, L. and Brown, D.D. (2004) Remodeling of the intestine during metamorphosis of Xenopus laevis. Proceedings of National Academy of Sciences of the USA, 8, 3720-3725.

[4] Nakajima, K., Fujimoto, K. and Yaoita, Y. (2005) Programmed cell death during amphibian metamorphosis. Seminar in Cell and Developmental Biology, 16, 271280. doi:10.1016/j.semcdb.2004.12.006

[5] Glucksman, A. (1951) Cell deaths in normal vertebrate ontogeny. Biological Review, 26, 59-86. doi:10.1111/j.1469-185X.1951.tb00774.X

[6] Imoh, H. (1986) Cell death during normal gastrulation in the newt, Cynops pyrrhogaster. Cell Differentiation, 19, 35-42. doi:10.1016/0045-6039(86)90023-0

[7] Sanders, E.K., Torkkeli, P.H. and French, A.S. (1997) Patterns of cell death during gastrulation in chick and mouse embryos. Anatomy Embryology, 195, 147-154. doi:10.1007/s004290050033

[8] Hensey, C. and Gautier, J. (1998) Programmed cell death during Xenopus development: A spatio-temporal analysis. Developmental Biology, 203, 36-48. doi:10.1006/dbio.1998.9028

[9] Cole, L.K. and Ross, L.S. (2001) Apoptosis in the developing zebrafish embryo. Developmental Biology, 240, 123-142. doi:10.1006/dbio.2001.0432

[10] Kerr, J.F.R., Harmon, B. and Searle, J. (1972) Apoptosis: Basic biological phenomenon with wide-range implications in tissue kinetics. British Journal of Cancer, 26, 239-257. doi:10.1038/bjc.1972.33

[11] Hensey, C. and Gautier, J. (1997) A developmental timer that regulates apoptosis at the onset of gastrulation. Mechanism of Development, 69, 183-195. doi:10.1016/S0925-4773(97)00191-3

[12] Hensey, C. and Gautier, J. (1999) Developmental regulation of induced and programmed cell death in Xenopus embryos. Annals of New York Academy of Sciences, 887, 105-119. doi:10.1111/j.1749-6632.1999.tb07926.x

[13] Greenwood, J. and Gautier, J. (2005) From oogenesis through gastrulation: Developmental regulation of apoptosis. Seminars in Cell and Developmental Biology, 16, 215-224. doi:10.1016/j.semcdb.2004.12.002

[14] Stack, J.H. and Newport, J.W. (1997) Developmentally regulated activation of apoptosis early in Xenopus gastrulation results in cyclin A degradation during interphase of the cell cycle. Development, 124, 3185-3195.

[15] Sible, J.C., Anderson, J.A., Lewellyn, A.L. and Maller, J.L. (1997) Zygotic transcription is required to block a maternal program of apoptosis in Xenopus embryos. Developmental Biology, 189, 335-346. doi:10.1006/dbio.1997.8683

[16] Maller, J.L., Gross, S.D., Schwab, M.S., Finkielstein, C.V., Taieb, F.E. and Qian Y.W. (2001) Cell cycle transitions in early Xenopus development. Novartis Foundation Symposia, 237, 58-73. 


\section{doi:10.1002/0470846666.ch6}

[17] Shiokawa, K., Kai, M., Higo, T., Kaito, C., Yokoska, J., Yasuhiko, Y., Kajita, E., Nagano, M., Yamada, Y., Shibata, M., Muto, T., Shinga, J., Hara, H., Takayama, E., Fukamachi, H., Yaoita, Y. and Igarashi, K. (2000) Maternal program of apoptosis activated shortly after midblastula transition by overexpression of S-adenosylmethionine decarboxylase in Xenopus early embryos. Comparative Biochemistry Physiology, B Biochemistry and Molecular Biology, 126, 149-155. doi:10.1016/S0305-0491(00)00193-0

[18] Kaito, C., Kai, M., Higo, T., Takayama, E., Fukamachi, H., Sekimizu, K. and Shiokawa, K. (2001) Activation of the maternally preset program of apoptosis by microinjection of 5-aza-2'-deoxycytidine and 5-methyl-2'-deoxycytidine-5'-triphosphate in Xenopus laevis embryos. Development, Growth, Differentiation, 43, 383-390. doi:10.1046/j.1440-169x.2001.00579.x

[19] Takayama, E., Higo, T., Kai, M., Fukasawa, M., Nakajima, K., Hara, H., Tadakuma, T., Igarashi K., Yaoita, Y. and Shiokawa, K. (2004) Involvement of caspase-9 in execution of the maternal program of apoptosis in Xenopus late blastulae overexpressed with S-adenosylmethionine decarboxylase. Biochemical and Biophysical Research Communications, 24, 1367-1375. doi:10.1016/j.bbrc.2004.10.179

[20] Carter, A.D. and Sible, J.C. (2003) Loss of XChk1 function triggers apoptosis after the midblastula transition in Xenopus laevis embryos. Mechanism of Development, 120, 315-323. doi:10.1016/S0925-4773(02)00443-4

[21] Kai, M., Kaito, C., Fukamachi, H., Higo, T., Takayama, E., Hara, H., Ohya, Y., Igarashi, K. and Shiokawa, K. (2003) Overexpression of S-adenosylmethionine decarboxylase (SAMDC) in Xenopus embryos activates maternal program of apoptosis as a "fail-safe" mechanism of early embryogenesis. Cell Research, 13, 147-158. doi:10.1038/sj.cr.7290159

[22] Wroble, B.N. and Sible, J.C. (2005) Chk2/Cds1 protein kinase blocks apoptosis during early development of Xenopus laevis. Developmental Dynamics, 233, 13591365. doi:10.1002/dvdy.20449

[23] Ruzov, A., Shorning, B., Mortusewicz, O., Dunican, D.S., Leonhard, T.H. and Meehan, R.R. (2009) MBD4 and MLH1 are required for apoptotic induction in xDNMT1depleted embryos. Development, 136, 2277-2286. doi:10.1242/dev.032227

[24] De Marco, N., Campanella, C. and Carotenuto, R. (2011) In $X$. laevis embryos high levels of the anti-apoptotic factor p27BBP/eIF6 are stage-dependently found in BrdU and TUNEL-reactive territories. Zygote, 19, 157-163. doi:10.1017/S0967199410000213

[25] Schuff, M., Siegel, D., Bardine, N., Oswald, F., Donow, C. and Knichel, W. (2009) FoxO genes are dispensable during gastrulation but required for late embryogenesis in Xenopus laevis. Developmental Biology, 15, 259-273.

[26] Trindade, M., Messenger, N., Papin, C., Grimmer, D., Fairclough, L., Tada, M. and Smith, J.C. (2003) Regulation of apoptosis in the Xenopus embryo by Bix3. Development, 130, 4611-4622. doi:10.1242/dev.00489
[27] Ikegami, R., Hunter, P. and Yager, T.D. (1999) Developmental activation of the capability to undergo checkpoint-induced apoptosis in the early zebrafish embryo. Developmental Biology, 15, 409-433. doi:10.1006/dbio.1999.9243

[28] Endo, T., Kusakabe, M., Sunadome, K., Yamamoto, T. and Nishida, E. (2011) The kinase SGK1 in the endoderm and mesoderm promotes ectodermal survival by downregulating components of the death-inducing signaling complex. Science of Signalisation, 18, 156.

[29] Wallingford, J.B., Seufert, D.W., Virta, V.C. and Vize, P.D. (1997) p53 activity is essential for normal development in Xenopus. Current Biology, 7, 747-757. doi:10.1016/S0960-9822(06)00333-2

[30] Malikova, M.A., Van Stry, M. and Symes, K. (2007) Apoptosis regulates notochord development in Xenopus. Developmental Biology, 311, 434-448. doi:10.1016/j.ydbio.2007.08.047

[31] Andreazzoli, M., Gestri, G., Angeloni, D., Menna, E. and Barsacchi, G. (1999) Role of Xrx1 in Xenopus eye and anterior brain development. Development, 126, 24512460.

[32] Yeo, W. and Gautier, J. (2003) A role for programmed cell death during early neurogenesis in Xenopus. Developmental Biology, 260, 31-45. doi:10.1016/S0012-1606(03)00222-7

[33] Kim, G.H., Park, E. and Han, J.K. (2005) The assembly of POSH-JNK regulates Xenopus anterior neural development. Developmental Biology, 286, 256-269. doi:10.1016/j.ydbio.2005.07.033

[34] Sugimoto, K., Okabayashi, K., Sedohara, A., Hayata, T. and Asashima, M. (2007) The role of XBtg2 in Xenopus neural development. Developmental Neurosciences, 29 , 468-479. doi:10.1159/000097320

[35] Tribulo, C., Aybar, M., Sanchez, S.S. and Mayor, R. (2004) A balance between the anti-apoptotic activity of Slug and the apoptotic activity of msx1 is required for the proper development of the neural crest. Developmental Biology, 275, 325-342. doi:10.1016/j.ydbio.2004.07.041

[36] Carl, T.F., Dufton, C., Hanken, J. and Klymkowsky, M.W. (1999) Inhibition of neural crest migration in Xenopus using antisense slug RNA. Developmental Biology, 213, 101-115. doi:10.1006/dbio.1999.9320

[37] Aybar, M.J., Nieto, A. and Mayor, R. (2003) Snail precedes slug in the genetic cascade required for the specification and migration of the Xenopus neural crest. Development, 30, 483-494. doi:10.1242/dev.00238

[38] La Bonne, C. and Bronner-Fraser, M. (2000) Snail-related transcriptional repressors are required in Xenopus for both the induction of the neural crest and its subsequent migration. Developmental Biology, 221, 195-205. doi:10.1006/dbio.2000.9609

[39] Mayor, R., Guerrero, N., Young, R.M., Gomez-Skarmeta, J.L. and Cuellar, C. (2000) A novel function for the Xslug gene: Control of dorsal mesendoderm development by repressing BMP-4. Mechanism of Development, 97, 4756. doi:10.1016/S0925-4773(00)00412-3

[40] Schneider, M., Schambony, A. and Wedlich, D. (2010) 
Prohibitin1 acts as a neural crest specifier in Xenopus development by repressing the transcription factor E2F1. Development, 137, 4073-4081. doi:10.1242/dev.053405

[41] De Marco, N., Iannone, L., Carotenuto, R., Biffo, S., Vitale, A. and Campanella, C. (2010) p27(BBP)/eIF6 acts as an anti-apoptotic factor upstream of Bcl-2 during Xenopus laevis development. Cell Death Differentiation, 17, 360-372. doi:10.1038/cdd.2009.128

[42] Hutson, L.D. and Bothwell, M. (2001) Expression and function of Xenopus laevis p75(NTR) suggest evolution of developmental regulatory mechanisms. Journal of Neurobiology, 49, 79-98. doi:10.1002/neu.1067

[43] Estabel, J. (2004).Apoptoses physiologiques et apoptoses expérimentalement induites au cours du développement de Xenopus laevis. Ph.D. Thesis, EPHE, Lyon.

[44] Poitras, L., Bisson, N., Islam, N. and Moss, T. (2003) A tissue restricted role for the Xenopus Jun N-terminal kinase MLK2 in cement gland and pronephric tubule differentiation. Developmental Biology, 254, 200-214. doi:10.1016/S0012-1606(02)00040-4

[45] Weber, R. (1964) Ultrastructural changes in regressing tail muscles of Xenopus laevis at metamorphosis. Journal of Cell Biology, 22, 481-487. doi:10.1083/jcb.22.2.481

[46] Kerr, J.F.R., Harmon, B. and Searle, J. (1974) An electron-microscope study of cell deletion in the Anuran tadpole tail during spontaneous metamorphosis with special reference to apoptosis of striated tail muscle fibres. Journal of Cell Science, 14, 571-585.

[47] Tata, J.R. (1996) Metamorphosis: An exquisite model for hormonal regulation of post-embryonic development. Biochemical Society Symposia, 62, 123-136.

[48] Shi, Y.B. and Ihizuya-Oka, A. (2001) Thyroid-hormone regulation of apoptotic tissue remodeling implications from molecular analysis of amphibian metamorphosis. Progress in Nucleic Acid Research and Molecular Biology, 65, 53-100. doi:10.1016/S0079-6603(00)65002-X

[49] Bertrand, S. and Laudet, V. (2001) La métamorphose des amphibiens: Un modèle prometteur pour étudier les protéases de la matrice. Médecine/Sciences, 17, 11951200. doi:10.1051/medsci/200117111195

[50] Dodd, M.H.I. and Dodd, J.M. (1976) Physiology of the Amphibia. In: Loft, B., Ed., Academic Press, New York.

[51] Su, Y., Damjanowski, S, Shi, Y. and Shi, Y.B. (1999) Molecular and cellular basis of tissue remodeling during amphibian metamorphosis. Histology Histopathology, 14, 175-183.

[52] Ishizuya-Oka, A., Hasebe, T. and Shi, Y.B. (2010). Apoptosis in amphibian organs during metamorphosis. Apoptosis, 15, 350-364. doi:10.1007/s10495-009-0422-y

[53] Tata, J.R. (2006) Amphibian metamorphosis as a model for the developmental actions of thyroid hormone. Molecular and Cellular Endocrinology, 26, 10-20. doi:10.1016/j.mce.2005.11.024

[54] Kanamori, A. and Brown, D.D. (1996) The analysis of complex developmental programmes: Amphibian metamorphosis. Genes Cells, 1, 429-435. doi:10.1046/j.1365-2443.1996.d01-251.x

[55] Du Pasquier, D., Rinheval, V., Sinzelle, L., Chesneau,
A., Ballagny, C., Sachs, L.M., Demeneix, B. and Mazabraud, A. (2006). Developmental cell death during Xenopus metamorphosis involves BID cleavage and caspase 2 and 8 activation. Developmental Dynamics, 235, 2083-2094. doi:10.1002/dvdy.20874

[56] Estabel, J., Mercer, A., Koenig, N. and Exbrayat, J.-M. (2003) Programmed cell death in Xenopus laenis metamorphosis development prior to, and during, metamorphosis. Life Science, 73, 3298-3306.

[57] Marsh-Armstrong, N., Cai, L. and Brown, D.D. (2004) Thyroid hormone controls the development of connections between the spinal cord and limbs during Xenopus laevis metamorphosis. Proceedings of National Academy of Sciences USA, 101, 165-170. doi:10.1073/pnas.2136755100

[58] Hughes, A.F. (1961) Cell degeneration in the larval ventral horn of Xenopus laevis. Journal of Embryology and Experimental Morphology, 9, 269-284.

[59] Prestige, M.C. (1965) Cell turnover in the spinal ganglia of Xenopus laevis tadpoles. Journal of Embryology and Experimental Morphology, 13, 63-72.

[60] Hourdry, J. and Beaumont, A. (1985) Les métamorphoses des amphibiens. Masson, Paris.

[61] Jenkins, S. and Straznicky, C. (1986) Naturally occurring and induced ganglion cell death. A retinal whole-mount autoradiographic study in Xenopus. Anatomical Embryology, 174, 59-66.

[62] Gaze, R.M. and Grant, P. (1992) Spatio-temporal patterns of retinal ganglion cell death during Xenopus development. Journal of Comparative Neurology, 315, 264-274. doi:10.1002/cne.903150303

[63] Udin, S.B. and Grant, S. (1999). Plasticity in the tectum of Xenopus laevis: Binocular maps. Program in Neurobiology, 59, 81-106. doi:10.1016/S0301-0082(98)00096-3

[64] Oppenheim, R.W. (1991) Cell death during development of the nervous system. Annual Review of Neurosciences, 14, 453-501. doi:10.1146/annurev.ne.14.030191.002321

[65] Robert, A. and Clarke, J.D.W. (1982) The neuronatomy of an Amphibian embryo spinal cord. Philosophical Transactions of Royal Society of London B, 296, 195-212. doi:10.1098/rstb.1982.0002

[66] Lamborghini, J.E. (1987) Disappearance of Rohon-Beard neurons from the spinal cord of Xenopus laevis. Journal of Comparative Neurology, 264, 47-55. doi:10.1002/cne.902640105

[67] Coen, L., Du Pasquier, D., Le Mevel, S., Brown, S., Tata, J., Mazabraud, A. and Demeneix, B.A. (2001) Xenopus $\mathrm{Bcl}-\mathrm{X}(\mathrm{L})$ selectively protects Rohon-Beard neurons from metamorphic degeneration. Proceedings of National Academy of Sciences USA, 98, 7869-7874.

[68] Cruz-Reyes, J. and Tata, J.R. (1995) Cloning, characterization and expression of two $\mathrm{Bcl}-2$ like cell survival genes. Gene, 158, 171-179. doi:10.1016/0378-1119(95)00159-4

[69] Nakajima, K. and Yaoita, Y. (2003) Dual mechanisms governing muscle cell death in tadpole tail during amphibian metamorphosis. Development Dynamics, 227, 246-255. doi:10.1002/dvdy.10300

[70] Nishikawa, A. and Hayashi, H. (1995) Spatial, temporal 
and hormonal regulation of programmed muscles cell death during metamorphosis of the frog Xenopus laevis. Differentiation, 59, 207-214. doi:10.1046/j.1432-0436.1995.5940207.x

[71] Sachs, L.M., Abdallah, B., Hassan, A. Levi, G., Read, J.C. and Demeneix, B.A. (1997) Apoptosis in Xenopus tadpole tail muscles involves Bax-dependent pathways. FASEB Journal, 11, 801-808

[72] Das, B., Schreider, A.M., Huag, H. and Brown, D.D. (2002) Multiple thyroid hormone-induced muscle growth and death programs during metamorphosis in Xenopus laevis. Proceedings of National Academy of Sciences USA, 99, 12230-12235. doi:10.1073/pnas.182430599

[73] Rowe, I., Le Blay, K., Du Pasquier, D., Palmier, K., Levi, G., Demeneix, B. and Coen, L. (2005) Apoptosis of tail muscle during amphibian metamorphosis involves a caspase 9-dependent mechanism. Developmental Dynamics, 233, 76-87. doi:10.1002/dvdy.20312

[74] Shi, Y.B. and Ishizuya-Oka, A. (1996) Biphasic intestinal development in amphibians: Embryogenesis and remodeling during metamorphosis. Current Topics in Developmental Biology, 32, 205-235.

doi:10.1016/S0070-2153(08)60429-9

[75] Ishizuya-Oka, A. and Ueda, S. (1996) Apoptosis and cell proliferation in the Xenopus small intestine during metamorphosis. Cell and Tissue Research, 286, 467-476. doi:10.1007/s004410050716

[76] Atkinson, B.G., Helbing, C. and Chen, Y.Q. (1994) Perspectives in comparative endocrinology. In: Davy, D.G., Tobe, S.S. and Peter, R.G., Eds., National Research Council of Canada, Ottawa, 416.

[77] Shi, Y.B. and Ishizuya-Oka, A. (1997) Autoactivation of Xenopus thyroid hormone receptor beta genes correlates with larval epithelial apoptosis and adult cell proliferation. Journal of Biomedical Science, 4, 9-18. doi:10.1007/BF02255588

[78] Shi, Y.B. and Ishizuya-Oka, A. (2001) Thyroid hormone regulation of apoptotic tissue remodeling: Implications from molecular analysis of amphibian metamorphosis. Progress in Nucleic Acid Research and Molecular Biology, 65, 53-100. doi:10.1016/S0079-6603(00)65002-X

[79] Ishizuya-Oka, A., Ueda, S., Inokuchi, T., Amano, T., Damjanovski, S., Stolow, M. and Shi, YB. (2001) Thyroid hormone-induced expression of sonic hedgehog correlates with adult epithelial development during remodeling of the Xenopus stomach and intestine. Differentiation, 69, 27-37. doi:10.1046/j.1432-0436.2001.690103.x

[80] Kaltenbach, J.C., Fry, A.E., Colpitts, K.M. and Faszewski, E.E. (2012) Apoptosis in the digestive tract of herbivorous Rana pipiens larvae and carnivorous Ceratophrys ornata larvae: An immunohistochemical study. Journal of Morphology, 273, 103-108. doi:10.1002/jmor.11010

[81] Hasebe, T., Kajita, M., Fujimoto, K., Yaoita, Y. and Ishizuya-Oka, A.(2007) Expression profiles of the duplicated matrix metalloproteinase-9 genes suggest their different roles in apoptosis of larval intestinal epithelial cells during Xenopus laevis metamorphosis. Developmental Dynamics, 236, 2338-2345. doi:10.1002/dvdy.21252

[82] Ishizuya-Oka, A. and Shi, Y.B. (2005) Molecular mecha- nisms for thyroid hormone-induced remodeling in the amphibian digestive tract: A model for studying organ regeneration. Development Growth Differentiation, 47, 601607. doi:10.1111/j.1440-169X.2005.00833.x

[83] Schreiber, A.M. and Brown, D.D. (2003) Tadpole skin dies autonomously in response to thyroid hormone at metamorphosis. Proceedings of National Academy of Sciences USA, 100, 1769-1774. doi:10.1073/pnas.252774999

[84] Tamori, Y. and Wakahara, M. (2000) Conversion of red blood cells (RBCs) from the larval to the adult type during metamorphosis in Xenopus: Specific removal of mature larval-type RBCs by apoptosis. International Journal of Developmental Biology, 44, 373-380.

[85] Yaoita, Y., Shi, Y.B. and Brown, D.D. (1990) Xenopus laevis alpha and beta thyroid hormone receptors. Proceedings of the National Academy of Sciences of the USA, 87, 7090-7094. doi:10.1073/pnas.87.18.7090

[86] Shi, Y.B. and Ishizuya-Oka, A. (1996) Biphasic intestinal development in amphibians: Embryogenesis and remodeling during metamorphosis. Current Topics in Developmental Biology, 32, 205-235. doi:10.1016/S0070-2153(08)60429-9

[87] Shi, Y.B., Li, Q., Damjanovski, S., Aano, T. and Ishizuya-Oka, A. (1998) Regulation of apoptosis during development: Input from the extracellular matrix (review). International Journal of Molecular Medicine, 2, 273-282.

[88] Shi, Y.B., Sachs, L.M., Jones, P., Li, Q. and IshizuyaOka, A. (1998) Thyroid hormone regulation of Xenopus laevis metamorphosis: Functions of thyroid hormone receptors and roles of extracellular matrix remodeling. Wound Repair Regeneration, 6, 314-322. doi:10.1046/j.1524-475X.1998.60407.x

[89] Berry, D.L., Schwartzman, R.A. and Brown, D.D. (1998) The expression pattern of thyroid hormone response genes in the tadpole tail identifies multiple resorption programs. Developmental Biology, 203, 12-23. doi:10.1006/dbio.1998.8974

[90] Ishizuya-Oka, A. and Shi, Y.B. (2005) Molecular mechanisms for thyroid hormone-induced remodeling in the amphibian digestive tract: A model for studying organ regeneration. Development Growth Differentiation, 47, 601607. doi:10.1111/j.1440-169X.2005.00833.X

[91] Ishizuya-Oka, A. and Shi, Y.B. (2008) Thyroid hormone regulation of stem cell development during intestinal remodeling. Molecular Cellular Endocrinology, 288, 71-78. doi:10.1016/j.mce.2008.02.020

[92] Hasebe, T., Hartman, R., Matsuda, H. and Shi, Y.B. (2006) Spatial and temporal expression profiles suggest the involvement of gelatinase A and membrane type 1 matrix metalloproteinase in amphibian metamorphosis. Cell and Tissue Research, 324, 105-116. doi:10.1007/s00441-005-0099-7

[93] Hasebe, T., Kajita, M., Iwabuchi, M., Ohsumi, K. and Ishizuya-Oka, A. (2011) Thyroid hormone-regulated expression of nuclear lamins correlates with dedifferentiation of intestinal epithelial cells during Xenopus laevis metamorphosis. Developmental Genes and Evolution, 221, 199-208. doi:10.1007/s00427-011-0371-7 
[94] Hasebe, T., Kajita, M., Shi, Y.B. and Ishizuya-Oka, A. (2008) Thyroid hormone-up-regulated hedgehog interacting protein is involved in larval-to-adult intestinal remodeling by regulating sonic hedgehog signaling pathway in Xenopus laevis. Developmental Dynamics, 237, 30063015. doi:10.1002/dvdy.21698

[95] Wang, G.J., Schmued, L.C., Andrews, A.M., Scallet, A.C., Slikker, W. and Binienda, Z. (2000) Systemic administration of domic acid-induced spinal cord lesions in neonatal rats. Journal of Spinal Cord Medicine, 23, 3139.

[96] Estabel, J. and Exbrayat, J.M. (2002) Localisation des récepteurs AMPA/kaïnate dans les organes périphériques chez Xenopus laevis par immunohistochimie. Revue Française d'Histotechnologie, 15, 9-14.

[97] Mouterfi, N., Moudilou, E., Estabel, J., König, N., Benyamin, Y. and Exbrayat, J.M. (2006) Effets d'un traitement pharmacologique par un antagoniste des récepteurs ionotropes du glutamate sur l'apoptose et l'expression des calpaïnes chez des têtards. Revue Française d'Histotechnologie, 19, 113-117.

[98] Mouterfi, N., Moudilou, E.N., Exbrayat J.M. and Brun, C.
(2007) Glutamate induced calpains-like expression in Xenopus laevis development. 14th European Congress of Herpetology, Porto, 19-23 September 2007, Abstracts, 25.

[99] Moudilou, E.N., Mouterfi, N., Exbrayat, J.M. and Brun, C. (2010) Calpains expression during Xenopus laevis development. Tissue and Cell, 42, 275-281. doi:10.1016/j.tice.2010.07.001

[100] Rowe, I., Coen, L., Le Blay, K., Le Mevel, S. and Demeneix, B.A. (2002) Autonomous regulation of muscle fibre fate during metamorphosis in Xenopus tropicalis. Developmental Dynamics, 224, 381-390. doi:10.1002/dvdy.10117

[101] Del Pino, E.M. and Medina, A. (1998) Neural development in the marsupial frog Gastrotheca riobambae. International Journal of Developmental Biology, 42, 723731.

[102] Haydar, T.H., Kuan, C.I., Flavell, R.A. and Rakic, P. (1999) The role of cell death in regulating the size and shape of the mammalian forebrain. Cerebral Cortex, 9, 621-626. doi:10.1093/cercor/9.6.621 